\title{
Literatur Riview Tentang Faktor Penyebab Klaim Tidak Layak Bayar BPJS Kesehatan Di Rumah Sakit Tahun 2020
}

\author{
Oktamianiza $^{1}$, Rahmadhani $^{2}$, Yulfa Yulia ${ }^{3}$, Helmi Mazra Putri ${ }^{4}$ \\ ${ }^{1,2,3,4}$ Program Studi D-3 Rekam Medis, STIKes Dharma Landbouw Padang
}

\begin{tabular}{l}
\hline Article Info \\
\hline Article history: \\
Received Jan 12, 2021 \\
Revised Feb 15, 2021 \\
Accepted Feb 23, 2021 \\
\hline
\end{tabular}

Keywords:

BPJS

Claims

INA-CBGs

Verifier

\begin{abstract}
ABSTRAK
Health service costs that are claimed by health care facilities to BPJS are set based on the provisions that have been formulated by the Ministry of Health as standardization of health service costs at INACBG rates. During the verification process by the BPJS verifier, the Ministry of Health still found several claims that were returned, one of which was the claim that was not feasible. Therefore, the researcher is interested in further examining the factors that cause the claim that BPJS health is not eligible to pay at the hospital. The results showed that the appropriateness of the administrative participation was an average of $66 \%$, the suitability of medical service administration was $25 \%$, the accuracy of disease diagnosis was $75 \%$, the primary diagnosis was $88 \%$, the accuracy of the secondary diagnosis was $88 \%$, the accuracy of the diagnosis code was 55\% correct. In this study, it can be concluded that the administrative completeness of the BPJS Health claim requirements in the hospital is still incomplete, due to differences in perceptions between internal verifiers and external verifiers, lack of knowledge and responsibility of health service workers on the importance of filling in complete, accurate and reliable medical record files. So the researchers suggest that there is periodic socialization to equalize perceptions about policies and standards in the payment process for health care costs. Besides that, health service officers who take an active role in filling out medical record files in order to apply the rules that have been set, so that problems related to claims that are not worth paying can be minimized so that health services as well.
\end{abstract}

\section{Corresponding Author:}

This is an open access article under the CC BY-SAlicense.

Oktamianiza,

Program Studi D-3 Rekam Medis, STIKes Dharma Landbouw Padang,

Jl. Jhoni Anwar No. 29 Ulak Karang Utara, Kec. Padang Utara, Kota Padang, Sumatera Barat.

Email: oktamianiza@gmail.com

\section{PENDAHULUAN}

Rumah sakit sebagai penyelenggara pelayanan kesehatan harus dapatmemberikan pelayanan yang paripurna dengan menyediakan pelayanan rawat inap, rawat jalan dan gawat darurat (Permenkes No. 3, 2020). Rekam Medis sebagai dukumen pasien yang berisikan semua pelayanan kesehatan yang telah diberikan tenaga kesehatan harus dapat terpelihara dan terisi dengan benar dan lengkap (Permenkes, 2013). Pengian rekam medis 
menjadi salah satu indikator dalam menilai mutu pelayanan yang diberikan kepada pasien, rekam medis dibuat dan dilengkapi setelah pasien menerima pelayanan agar data yang dicatat lengkap dan terisi pada kolom yang telah disediakan, setiap pencatatan rekam medis harus disertai nama dan tanda tangan petugas pelayanan kesehatan hal ini mempermudah pertanggungjawaban atas pencatatan. Apabila terjadi pembetulan maka dapat dilakukan dengan pencoretan tanpa menghilangkan catatan yang dibetulkan dan dibubuhi paraf (Permenkes RI, No. 269/Menkes/Per/III/2008).

Upaya yang disepakati seluruh pemangku kepentingan untuk dijalankan oleh BPJS kesehatan adalah melakukan penerapan model pembayaran prospektif (Juknis Verfikasi Klaim, 2014). Pada saat ini proses verifikasi oleh verifikator BPJS masih ditemukan beberapa klaim yang dikembalikan yaitu klaim yang tidak purifikasi, klaim yang tidak sesuai dan klaim yang tidak layak. Klaim tidak layak bayar menjadi bahan perbaikan untuk diusulkan kembali agar dapat dilakukan penggatian biaya oleh BPJS.

Berdasarkan hasil penelitian Tri Wahyuni, faktor penyebab klaim BPJS tidak layak adalah Man (SDM) petugas medis yaitu dokter dan petugas rekam medis atau petugas grouping. Money (uang) yang dapat menyebabkan terjadi kerugian baik bagi pasien maupun bagi rumah sakit, misalnya tarif rumah sakit Rp. 35.715.961 dan tarif INA-CBGs senilai 38.474.600, berarti terdapat perbedaan dari tarif yang telah ditetapkan. Material (bahan), terdapatnya perbedaan obat-obatan, pemberian jasa dokter serta barang medis habis pakai yang tidak sesuai dengan aturan BPJS, misalnya pemberian paket obat kronis sejumlah 86 kasus, sedangkan klaim yang dilakukan sebanyak 109 kasus. Market yaitu petugas yang berperan dalam mengajukan klaim tidak mengikuti aturan pelayanan sehingga akan berdampak pada pembiayaan pelayanan kesehatan rumah sakit (Wahyuni, 2015).

Sedangkan menurut penelitian Vera Otifa di Layanan Rawat Jalan Rumah Sakit Jiwa Prof Dr Soerojo Magelang tahun 2016, Faktor penyebab klaim tidak layak diantaranya Komunikasi pimpinan, sikap dokter, sikap verifikator BPJS Kesehatan, dan tidak adanya standar operasional prosedur dalam menentukan langkah dalam menetapkan klaim tidak layak bayar merupakan faktor penyebab terjadinya klaim tidak layak bayar di Layanan Rawat Jalan RSJS hal ini juga berdampak pada mutu rumah sakit dan dengan adanya klaim tidak layak ini maka juga akan menimbulka kerugian karena tidak adanya ganti rugi atas pelayanan kesehatan yang telah di berikan rumah sakit sebelumnya kepada pasien (Otifa, 2016).

Pada literatur riview ini, penulis memfokuskan pada deskripsi faktor penyebab klaim tidak layak bayar BPJS Kesehatan di rumah sakit seperti faktor kesesuaian administratif kepesertaan, kesesuaian administratif pelayanan medik, ketepatan diagnosis penyakit, ketepatan kodefikasi penyakit, kelengkapan dan kekonsistenan pengisian rekam medis. hal ini dikarenakan melihat pentingnya ketepatan dan kelengkapan berkas dalam melakukan prosedur klaim BPJS kesehatan di rumah sakit dan besarnya pengaruh klaim tidak layak bayar terutama pada finansial rumah sakit (Mutia, 2016).

\section{METODE PENELITIAN}

Jenis penelitian ini adalah penelitian kuantitatif dengan metode kajian literatur riview dengan analisisis deskriptif yang bertujuan untuk mendapatkan gambaran dan informasi. Pengumpulan data yang digunakan secara literature riview ini dengan menggunakan data penelitian yang sebelumnyaserta mengacu pada buku referensi yang mengkait dari penelitian yang dilakukan.

Objek penelitianu ini yaitu berkas rekam medis pasien peserta jaminan kesehatan nasional BPJS Kesehatan yang dikembalikan. Sumber pustaka yang digunakan dalam literatur riview ini melibatkan 4 pustaka dari jurnal. Analisis data juga dilakukan dengan 
menggunakan teknik literatur riview diantaranya mencari kesamaan (compare), ketidaksamaan (contrast), pandangan (critize), bandingkan (synthesize) dan ringkasan (summarize).

\section{HASIL DAN PEMBAHASAN}

\subsection{Hasil}

Hasil penelitian didapatkan berdasarkan literatur riview dapat diuraikan sebagai berikut :

\section{Faktor Kesesuaian Administratif Kepesertaan}

Berdasarkan hasil penelitian jurnal 1 yang dilakukan oleh (Linda Megawati dan Rita Dian Pratiwi, 2016) didapatkan deskripsi faktor kesesuain administrasi kepesertaan pada laporan individual pasien 6 (16\%) lengkap dan 32 (84\%) tidak lengkap karena salah enteri item seperti No. SEP, kelas perawatan, tanggal masuk, berdasarkan kartu BPJS sebesar 4 lembar atau 7\%, karena tidak melampirkan kartu BPJS asli/tidak aktif lebih dari separuh yaitu $89 \%$.

Sedangkan menurut penelitian dari jurnal 3 oleh (Ayu Frista Putri dan Savitri Citra Budi, 2017) deskripsi faktor administrasi kepesertaan 51 (85\%) lengkap dan 9 (15\%) tidak lengkap, item paling banyak ketidaklengkapannya yaitu lembar fotokopi kartu keluarga sebanyak 6 (10\%). Oleh sebab itu, deskripsi kesesuaian administrasi kepesertaan berdasarkan analisis jurnal masih terjadi kesalahan dalam proses pengklaiman BPJS Kesehatan seperti kelas perawatan, tanggal masuk, pada lembar syarat fotocopy kartu BPJS, fotocopi identitas diri ( KK) dan input SEP.

\section{Faktor kesesuaian administratif pelayanan medik}

Berdasarkan hasil penelitian jurnal 1 oleh (Linda Megawati dan Rita Dian Pratiwi, 2016) didapatkan deskripsi faktor administrasi pelayanan medik yaitu lembar syarat laporan individual pasien/pelayanan didapatkan lebih dari separuh yaitu sebesar $84 \%$ karena salah enteri data dan kurang dari separuh $16 \%$ lembar syarat yang lengkap. Lembar laporan penunjang sebanyak 7 lembar (18\%) tidak lengkap karena tidak melampirkan penunjang dan $31(82 \%)$ lengkap. Selanjutnya menurut penelitian dari jurnal 3 oleh (Ayu Frista Putri dan Savitri Citra Budi, 2017) deskripsi faktor administrasi pelayanan medik didapatkan hasil 14 (23,33\%) lengkap dan 46 (76,77\%) tidak lengkap, item paling banyak ketidaklengkapannya yaitu lembar penunjang sebanyak $22(36,67 \%)$ dan penepatan LOS $(18,33 \%)$.

Sedangkan menurut jurnal 4 yang dilakukan oleh (Muhammad Tijar Gifari dan Fajar Ariyanti, 2019) deskripsi faktor administrasi pelayanan medik yaitu pada Informasi Rekam Medis 68 klaim $(51,5 \%)$ ditolak, karena resume medis yang tidak lengkap dan hasil penunjang yang tidak tersedia. Oleh sebab itu, deskripsi kesesuaian administrasi pelayanan medis berdasarkan analisis jurnal masih ditemukan kesalahan dalam proses pengklaiman BPJS Kesehatan yaitu kesalahan pengisian dan kelengkapan berkas resume medis, laporan penunjang, penetapan episode rawatan, penulisan diagnosa dan pemberian kode penyakit serta pengesahan tanda tangan DPJP pada lembar INA-DRG dan penepatan LOS.

\section{Faktor ketepatan diagnosis penyakit}

Berdasarkan hasil penelitian jurnal 2 oleh (Oktamianiza, 2016) didapatkan hasil deskripsi kejelasan penulisan diagnosa utama $71 \%$ sedangkan ketidakjelasan penulisan diagnosa utama sebanyak 29 berkas (29\%) karena kurangnya tanggung jawab dokter, kelengkapan penulisan diagnosa utama sebanyak $82 \%$ dan ketidaklengkapan penulisan diagnosa utama sebanyak 18 berkas (18\%) karena adanya diagnosa singkatan, ketepatan 
diagnosa utama sebanyak 52\% dan ketidaktepatan diagnosa utama sebanyak 24 berkas (24\%) karena pemilihan antara diagnosa utama dengan sekunder.

Sedangkan menurut jurnal 3 yang dilakukan oleh (Ayu Frista Putri dan Savitri Citra Budi, 2017) didapatkan deskripsi ketepatan diagnosis pada diagnosa utama sebanyak $100 \%$ lengkap dan diagnosa sekunder $53(88,33 \%)$ lengkap serta $7(3,33 \%)$ tidak lengkap, ketidaklengkapan masih terdapat pada penulisan diagnosa sekunder atau tambahan sebanyak $7(3,33 \%)$

Oleh sebab itu, deskripsi ketepatan diagnosa penyakit berdasarkan analisis jurnal masih ditemukan kesalahan dalam penetapan diagnosa penyakit yaitu pengaruh dari kejelasan penulisan diagnosa, kurangnya tanggung jawab dokter, adanya diagnosa singkatan, kelengakapan penulisan diagnosa serta penetapan diagnosa primer dengan diagnosa sekunder.

\section{Faktor ketepatan kodefikasi penyakit}

Berdasarkan hasil penelitian jurnal 2 oleh (Oktamianiza, 2016) didapatkan hasil deskripsi ketepatan kode diagnosa utama sebanyak 52\% dan ketidaktepatan kode diagnosa utama sebanyak 48 berkas (48\%) karena kurang ketelitian petugas koder. Selanjutnya menurut jurnal 3 yang dilakukan oleh (Ayu Frista Putri dan Savitri Citra Budi, 2017) ketepatan kodefikasi penyakit sebanyak $5(8,33 \%)$ karena kode sekunder dan prosedur tidak ada. Sedangkan menurut jurnal 4 yang dilakukan oleh (Muhammad Tijar Gifari dan Fajar Ariyanti, 2019) didapatkan hasil ketepatan kodefikasi, sebanyak 57 klaim (43,5\%) ditolak karena petugas koder hanya melihat kode pada ICD-10 volume 3 tidak merujuk pada volume 1 sebagai final dari kode diagnosa penyakit pasien.

Oleh sebab itu, deskripsi ketepatan kodefikasi penyakit berdasarkan analisis jurnal masih ditemukan kesalahan dalam pemberian kode diagnosa penyakit yaitu kurang telitinya pihak koder dalam penetapan kode, pemberian kode diagnosa sekunder dan tindakan untuk menunjang ketepatan kode diagnosa utama dan petunjuk penggunaan ICD10 untuk merujuk kode pada Vol. 3 dan Vol. 1 ICD-10.

\subsection{Pembahasan}

Analisa jurnal dilakukan dengan menggunakan teknik literatur riview antara lain mencari kesamaan (compare), ketidaksamaan (contrast), pandangan (critize), bandingkan (synthesize), dan ringkasan (summarize) terhadap beberapa penelitian dari jurnal dapat diuraikan sebagai berikut :

a. Kesamaan (Compare)

Dari lima literatur yang telah dianalsis, terdapat kesamaan mendasar terhadap adanya ketidaklengkapan persyaratan dalam pengajuan berkas klaim. Kesamaan dilihat dari kelengkapan berkas administrasi kepesertaan yang masih terdapat kesalahan dalam pengisian dan ketidaklengakapan berkas. Diantaranya variabel yang sangat penting belum memenuhi standar penetapan persyaratan berkas klaim BPJS Kesehatan yaitu kesalahan pada kartu BPJS pasien dan kelengkapan berkas pendaftaran pasien JKN. Kesalahan pada kartu BPJS pasien disebakan karena keaslian kepemilikkan kartu BPJS dimana ada beberapa kasus pasien menggunakan kartu BPJS anggota keluarga lain untuk mendapatkan layanan kesehatan, sedangkan menurut ketentuannya setiap anggota keluarga mempunyai kartu BPJS masing-masing jika keluarga tersebut sudah mendaftar ke pihak JKN dan kartu tersebut sudah ada nama kepemilikkan masing-masing sehingga hanya bisa digunakan oleh nama keluarga yang tertera pada kartu BPJS.

Sedangkan kesalahan pada kelengkapan berkas pendaftaran pasien JKN karena petugas yang kurang teliti dalam penginputan data dan pemeriksaan berkas saat pendaftaran yang dibutuhkan untuk digunakan pada proses klaim nantinya ke pihak BPJS. 
Kelengkapan berkas pendaftaran pasien JKN seperti No.SEP, poli tujuan, tanggal masuk, kelas perawatan, lampiran fotokopi kartu keluarga.

Dilihat dari administrasi pelayanan medis yang masih terdapat kesalahan data dan formulir yang dibutuhkan sebagai persyaratan pihak BPJS untuk mencairkan dana pelayanan ke rumah sakit yaitu pada pengisian resume medis seperti tidak adanya tanda tangan dokter penanggung jawab pasien (DPJP) yang bertugas dan penetapan hari rawatan, kekurangan berkas laporan penunjang pasien seperti hasil labor (EKG, USG, Rotgen, dll), kesalahan pemberian kode seperti penetapatan kode diagnosa utama dan pemberian kode diagnosa sekunder serta penulisan diagnosa penyakit pasien oleh dokter yang kurang jelas, lengkap dan tepat sehingga berdampak pada pemberian kode yang dilakukan oleh koder rumah sakit.

b. Ketidaksamaan (Contrast)

Dari lima jurnal tersebut juga ditemukan ketidaksamaan antara satu sama lain diantaranya kebijakan dan persepsi masing-masing rumah sakit dalam proses pengklaiman serta tingkat pengetahuan rekam medis dan verifikator rumah sakit. Hal ini terlihat beberapa rumah sakit yang belum menjalankan ketentuan yang ditetapkan pihak BPJS karena adanya perbedaan pemahaman dan persepsi petugas masing-masing rumah sakit dalam mengartikan kebijakan yang telah ditetapkan oleh pihak BPJS. Oleh sebab itu, diperlukan sosialiasasi secara berkala antar verifikator rumah sakit dengan verifikator BPJS dalam menyamakan persepsi dan Update ilmu tentang pemahaman kebijakan dan standar yang baru ditetapkan pihak BPJS.

Dilihat dari petugas rekam medis, beberapa rumah sakit yang sudah kompeten namun proses klaim terkendala karena ketelitian verifikator dalam pengecekkan berkas persyaratan klaim dan melakukan tugas sesuai standar ketentuan dan kebijakan masingmasing terhadap prosedur penetapan standar klaim yang berbeda.

c. Pandangan (Critize)

Berdasarkan analisis dan telaah dari kelima jurnal, terlihat bahwa Kelengkapan pengisian data dan formulir persyaratan klaim masih banyak yang belum memenuhi standar BPJS Kesehatan. Hal ini dapat terjadi karena kompetensi, pengetahuan dan tanggung jawab setiap petugas kesehatan yang memiliki tanggung jawab dalam proses klaim masih kurang baik.

Adanya ketidaklengkapan persyaratan berkas klaim ini maka akan terjadi pengembalian berkas ke rumah sakit yang melakukan proses klaim atau yang sering disebut pending klaim hingga adanya permasalahan yang sangat krusial sekali dan perlu jadi perhatian yaitu berkas klaim yang ditolak atau tidak layak bayar. Tentunya hal ini sangat berdampak sekali pada operasi pelayanan kesehatan rumah sakit karena finansial terganggu maka ketersediaan alat kesehatan, kinerja petugas dan mutu rumah sakit juga akan terganggu. Oleh sebab itu, teknologi dan pengetahuan semakin berkembang, dewasa ini pengembangan diri dan pengetahuan serta update ilmu bagi petugas layanan kesehatan sangatlah penting terutama petugas yang bersangkutan dalam prosedur klaim serta menjadi fokus utama rumah sakit untuk memberikan sosialisasi dan peningkatan keilmuan bagi petugas pelayanan agar penolakan dan kesalahan dalam proses klaim dapat diminimalisir.

d. Ringkasan (Summarize)

Menurut penelitian (Kusumawati, 2018), adanya klaim pending sebabkan oleh 4 faktor yaitu kesalahan dalam proses koding, kesalahan dalam proses input, kesalahan dalam penempatan diagnosis dan ketidaklengkapan resume medis. Uraian tujuan literatur riview disajikan sebagai berikut :

1. Kesesuaian Administratif Kepesertaan

Berdasarkan analisis literatur riview dari lima jurnal adanya kesalahan administrasi kepesertaan karena kesalahan dalam persyaratan pendaftaran pasien seperti 
ketersediaan kartu BPJS kesehatan asli dan fotcopi, fotocopi identitas diri (KK) dan input SEP. Pada proses persetujuan klaim petugas verifikator BPJS mencocokkan seluruh administrasi dengan data kepesertaan pasien. Ketika tidak ada fotokopi kartu BPJS, fotokopi KTP atau fotokopi KK yang dilampirkan, maka persyaratan klaim tidak disetujui oleh verifikator BPJS (Ayu fiska putri \& Budi, 2017).

2. Kesesuaian Administratif Pelayanan Medik

Berdasarkan analisis literatur riview dari lima jurnal adanya kesalahan administrasi pelayanan medik karena kesalahan dalam pengisian dan kelengkapan berkas resume medis, laporan penunjang, penetapan episode rawatan, penulisan diagnosa dan pemberian kode penyakit serta pengesahan tanda tangan DPJP pada lembar INA-DRG dan penepatan LOS. (Malonda, Rattu dan soleman, 2014).

3. Ketepatan Diagnosa Penyakit

Berdasarkan analisis literatur riview dari lima jurnal adanya kesalahan ketepatan diagnosa penyakit karena pengaruh dari kesalahan dalam penetapan diagnosa penyakit yaitu pengaruh dari kejelasan penulisan diagnosa, kurangnya tanggung jawab dokter, adanya diagnosa singkatan, kelengakapan penulisan diagnosa serta penetapan diagnosa primer dengan diagnosa sekunder. Evaluasi terhadap kualitas rekam medis sangat berguna dalam menjamin konsistensi dan kelengkapan isinya, sehingga kode penyakit yang dihasilkan akurat dan sesuai dengan aturan umum koding morbiditas ICD-10 (Oktamianiza, 2016).

4. Ketepatan Kode Penyakit

Berdasarkan analisis literatur riview dari lima jurnal adanya kesalahan ketepatan kode penyakit karena kurang telitinya pihak koder dalam penetapan kode, pemberian kode diagnosa sekunder dan tindakan untuk menunjang ketepatan kode diagnosa utama dan petunjuk penggunaan ICD-10 untuk merujuk kode pada Vol. 3 ke Vol.1 ICD-10.

\section{KESIMPULAN}

Berdasarkan hasil review literatur yang dilakukan mengenai faktor penyebab klaim tidak layak bayar diperoleh kesimpulan sebagai berikut:

1. Kesesuaian administratif kepesertaan didapatkan berkas persyaratan klaim administrasi kepesertaan rata-rata belum sesuai.

2. Kesesuaian administratif pelayanan medik didapatkan beberapa rumah sakit masih terbilang kurang sesuai.

3. Ketepatan diagnosa penyakit masih terbilang rendah.

4. Pemberian kode penyakit masih kurang baik dan penulisan diagnosa dari dokter juga belum jelas.

Saran dari peneliti yaitu sebaiknya penelitian ini lebih dikembangkan dengan kajian penelitian melihat data langsung ke rumah sakit tentang faktor penyebab klaim tidak layak bayar karena permasalahan ini sangat krusial dan dibutuhkan rumah sakit sebagai bahan evaluasi dalam proses pengklaiman asuransi khususnya BPJS Kesehatan menambah jumlah sampel serta dapat menjabarkan secara jelas frekuensi munculnya permasalahan klaim tidak layak bayar di rumah sakit.

\section{UCAPAN TERIMA KASIH}

Pada kesempatan ini peneliti ingin mengucapkan terima kasih kepada Ketua Program Studi dan Ketua STIKes Dharma Landbouw yang telah banyak membantu sehingga peneliti dapat menyelesaikan penelitian ini dan pihak-pihak yang telah memberikan masukan dan bantuan kepada peneliti. 


\section{REFERENCES}

Ayu Fiska Putri, \& Budi, Savitri Citra. (2017). Hubungan Kelengkapan Persyaratan Klaim Terhadap Persetujuan Klaim Oleh Verifikator Bpjs Di Rsup Dr.Soeradji Tirtonegoro Klaten. Hubungan Kelengkapan Persyaratan Klaim Terhadap Persetujuan Klaim Oleh Verifikator Bpjs Di Rsup Dr.Soeradji Tirtonegoro Klaten, 1-10.

Gifari, muhammad tijar, \& Ariyanti, F. (2019). analisis persetujuan klaim BPJS kesehatan pada pasien rawat inap. analisis persetujuan klaim BPJS kesehatan pada pasien rawat inap, 08(04), 156-166. https://doi.org/10.33221/jikm.v8i04.415. Diakses tanggal 16 November 2020, pukul 13.20 Wib.

Hatta, Gemala. 2004. Pedoman Manajemen Informasi Kesehatan di Sarana Pelayanan Kesehatan. Jakarta: Universitas Indonesia.

Hasibuan, M. (2007). Manajemen Sumber Daya Manusia. Jakarta: Bumi Aksara.

Kesehatan, B. (2007). Petunjuk Teknis Verifikasi Klaim BPJS. 978-979.

Kusumawati, A. N. (2018). Faktor - Faktor Penyebab Pending Klaim Rawat Inap Di Rsud Koja Tahun 2018. 47(1), 2018-2021.

Megawati, L., \& Pratiwi, R. D. (2016). Faktor-Faktor Penyebab Pengembalian Berkas Persyaratan Klaim BPJS Pasien Rawat Inap di RS PKU Muhammadiyah Yogyakarta. $1(1), 36-43$.

Mutia, H. (2016). Gambaran Klaim Peserta Jaminan Kesehatan Nasional Yang Ditolak Pada Layanan Rawat Jalan Di Rumah Sakit Singaparna Medika Trauma Citra Utama Kabupaten Tasikmalaya Jawa Barat Tahun 2016. Gambaran Klaim Peserta Jaminan Kesehatan Nasional Yang Ditolak Pada Layanan Rawat Jalan Di Rumah Sakit Singaparna Medika Trauma Citra Utama Kabupaten Tasikmalaya Jawa Barat Tahun 2016.

Oktamianiza. (2016). Ketepatan Pengodean Diagnosa Utama Penyakit Pada Rekam Medis Pasien Rawat Inap JKN (Jaminan Kesehatan Nasioanal) Di Rsi Siti Rahmah Padang Tahun 2016. X(72), 159-167.

Otifa, V. (2016). Klaim Tidak Layak Bayar Peserta Jaminan Kesehatan Nasional Di Layanan Rawat Jalan Rumah Sakit Jiwa Prof Dr Soerojo Magelang.

PAMJAKI.(2005). Dasar-Dasar Asuransi Kesehatan Bagian A. Jakarta.

Permenkes RI, No. 269/Menkes/Per/Iii/2008 Tentang Rekam Medis ( Http : // Ngada. Org / Menkes269-2008. Htm ). (N.D.).

Permenkes RI , No 55 tahun 2013. Tentang Penyelenggaraan Pekerjaan Perekam Medis: Jakarta ( http: // permenkes-no-55-tahun-2013.html ). (n.d.). Diakses tanggal 17 November 2020, pukul 10.10 Wib.

Permenkes RI , No. 03/Menkes/Per/III/2020 tentang Klasifikasi Dan Perizinan Rumah Sakit (http : // ngada. org / menkes03-2020. htm). Diakses tanggal 15 November 2020, 
pukul 08.00 Wib.

Wahyuni, T. (2015). Analisis Faktor Penyebab Klaim Bpjs Tidak Layak Di Rumah Sakit Pku Muhammadiyah Unit Ii Yogyakarta.

\section{BIOGRAPHIES OF AUTHORS}

\begin{tabular}{|c|c|}
\hline & $\begin{array}{l}\text { Oktamianiza, Gelar D3 diperoleh dari Akademi Perekam Medis dan Informasi } \\
\text { Kesehatan pada Apikes Dharma Landbouw Padang pada tahun 2001, Gelar S1 } \\
\text { diperoleh dari Fakultas Kesehatan Masyarakat Universitas Indonesia tahun } 2004 \text { dan } \\
\text { Magister Kesehatan diperoleh pada Fakultas kesehatan Universitas Andalas tahun } 2012 \\
\text { saat ini aktif sebagai dosen tetap pada prodi D3 Rekam Medis dan Informasi Kesehatan } \\
\text { STIKes Dharma Landbouw Padang dan menjabat sebagai Ketua Prodi. }\end{array}$ \\
\hline 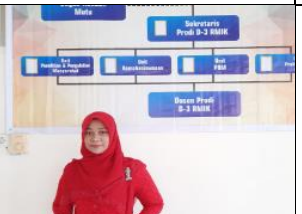 & $\begin{array}{l}\text { Rahmadhani, Gelar D3 diperoleh dari Akademi Kebidanan pada Akbid Dharma } \\
\text { Landbouw Padang pada tahun 2008, Gelar D4 Bidan Pendidik diperoleh dari Stikes } \\
\text { Ranah Minang Padang, fakultas Kedokteran Universitas Andalas tahun } 2020 \text { diperoleh } \\
\text { Magister Kebidanan saat ini aktif sebagai dosen tetap pada prodi D3 Rekam Medis dan } \\
\text { Informasi Kesehatan STIKes Dharma Landbouw Padang. }\end{array}$ \\
\hline 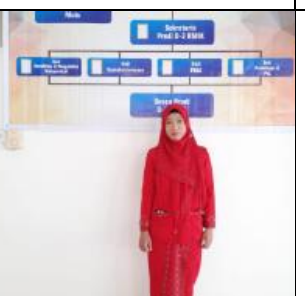 & $\begin{array}{l}\text { Yulfa Yulia, Gelar D3 diperoleh dari Jurusan Rekam Medis dan Informasi Kesehatan } \\
\text { pada STIKes Dharma Landbouw Padang pada Tahun 2014, Gelar DIV diperoleh dari } \\
\text { Jurusan Manajemen Informasi Kesehatan Fakultas Kesehatan Universitas Esa Unggul } \\
\text { Jakarta Tahun 2017, Magister Kesehatan Masyarakat diperoleh pada Jurusan } \\
\text { Kesehatan Masyarakat Universitas Fort De Kock Bukittinggi Tahun 2020, saat ini aktif } \\
\text { sebagai dosen tetap pada Prodi D3 Rekam Medis dan Informasi Kesehatan STIKes } \\
\text { Dharma Landbouw Padang. }\end{array}$ \\
\hline
\end{tabular}

